\title{
الذكاء الثقافي للدى مديري المدارس الدولية وعلاقته بسلوك المواطنة التنظيمية للمعلمين
}

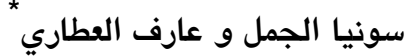

تاريخ قبوله 2019/7/16

2019/4/16 تاريخ تسلم البحث

Cultural Intelligence of International School Principals and its Relation to the Organizational Citizenship Behavior of Teachers

Sonia AL Jamal and Aref Al Attari, Yarmouk University, Jordan.

Abstract: This study aimed at identifying the level of cultural intelligence among the principals of international schools in Amman Governorate and its relation to teachers' "organizational citizenship behavior", from the perspective of the teachers of these schools. The study used the descriptive method. A questionnair consisting of (33) items covering the 'cultural intelligence' and another questionnaire for the 'organizational citizenship behavior' comprising 19 items were administered to a cluster sample of 494 teachers in 30 schools. The study found that both of the level of cultural intelligence among international school principals (3.96) and the level of teachers' practice of organizational citizenship behavior (3.41) were high. The results also showed a statistically significant positive relation between the level of cultural intelligence among international school principals and teachers' citizenship behavior in these schools. Cognitive and motivational cultural intelligence contributed statistically to predicting the behavior of organizational citizenship.

(Keywords: Cultural Intelligence, Organizational Citizenship Behavior, Principals of International Schools in Jordan, Teachers of International Schools in Jordan)

وتزداد الحاجة للكفايات الثقافية في المدارس بشكل عام وفي

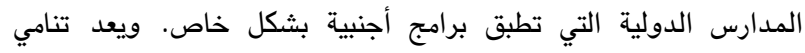

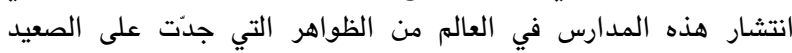

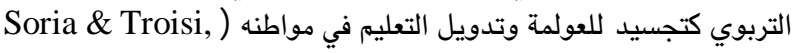

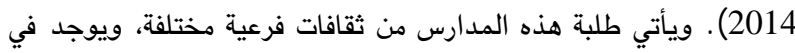

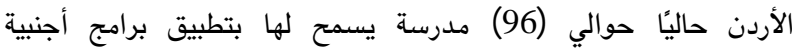
. (http://www.moe.gov.jo/ar/node/22560)

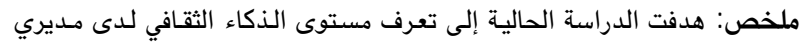

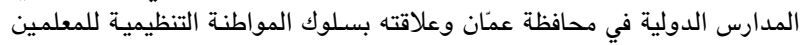

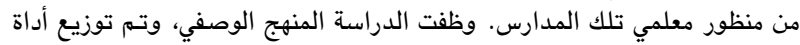

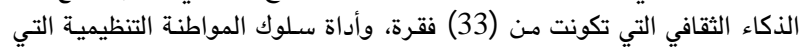

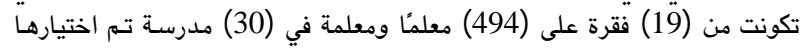

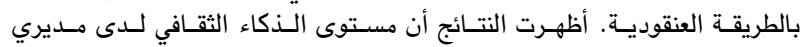

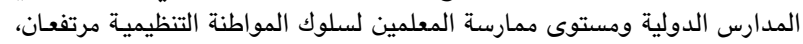

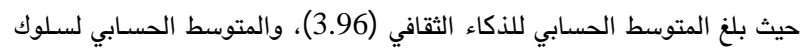

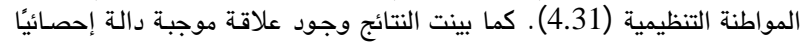

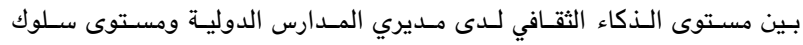

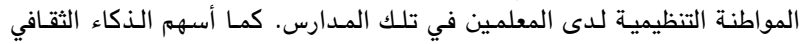

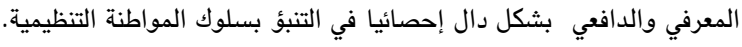

(الكلمات المفتاحية: الذكاء الثقافي، سلوك المواطنة التنظيمية، مديرو المدارس الدولية في الأردن، معلمو المدارس الداءلي، الدولية في الأردن)

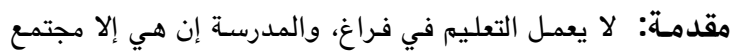

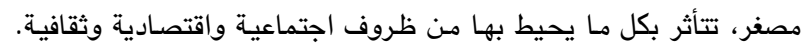

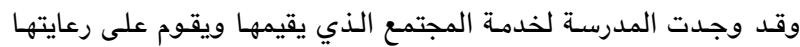

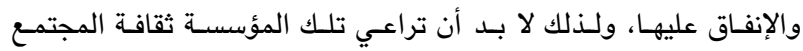

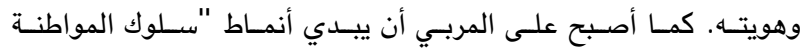
التنظيمية" المرغوب فيها من حيث الحرص على ألى خير المئ المؤسسة ومصلحتها أنها

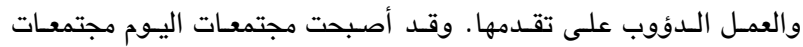

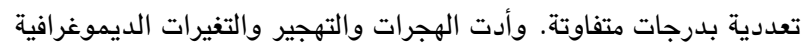

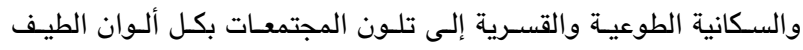

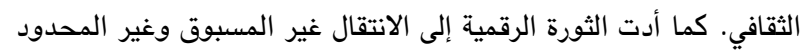

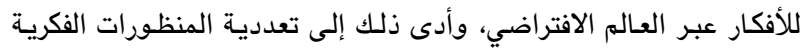

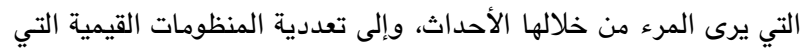

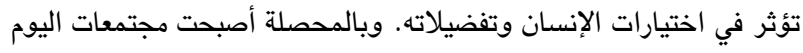

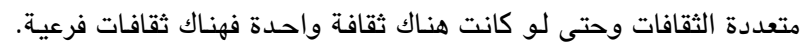

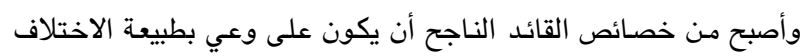

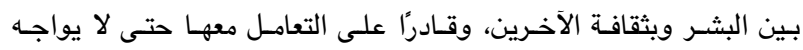

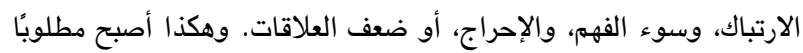

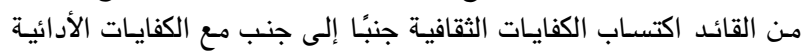

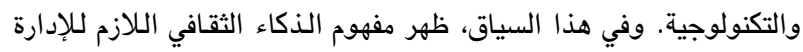

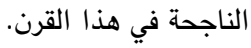
(C) حقوق الطبع محفوظة لجامعة اليرموك، اربد، الأردن. 
تربط بين سلوك المواطنة التظيمية ومداخل تنظيمية أخرى في

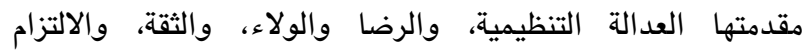

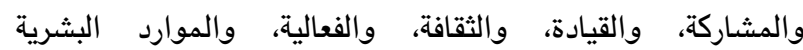

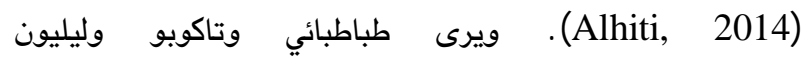
(Tabatabei ,Takapoo, Leilaeyoun, 2015)

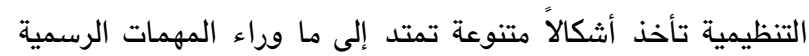

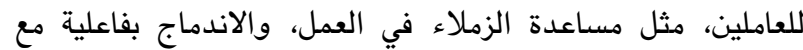
النشاطات التنظيمية، وحضور الوظائف التطوعية، وتجنب الصراعات التاتدات فاعلية غير الضرورية. واعتمد الباحثان في الدراسة الحالية على النموذج الخماسي

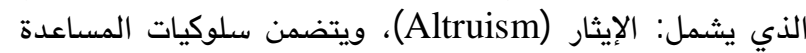
مثل مساعدة العاملين الجدد ومساعدة الزمار الزملاء في إتمام أعمالهم

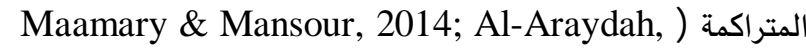
2012)؛ والكياسة (Courtesy)، وهي محاولة الموظف تجنب

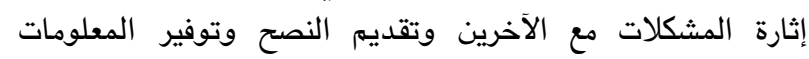
الضرورية، واحترام رغبات الزملاء (Al-Araydah, 2012)؛

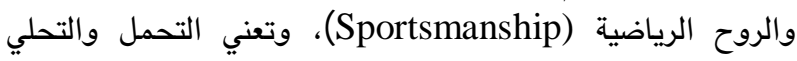

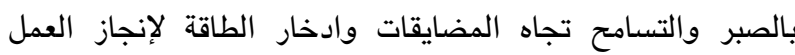

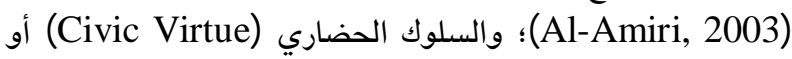

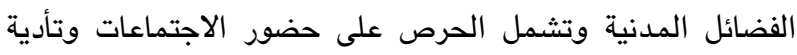

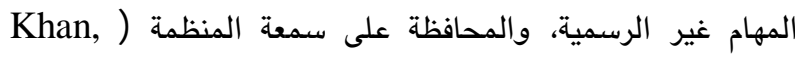

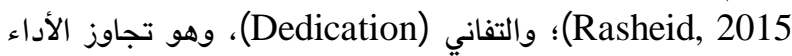
المستوى المعروف أو المتوقع (Al-Sheemat, 2007)، ويحتاج القادة التربويون، خاصة في المدارس الدولية التي

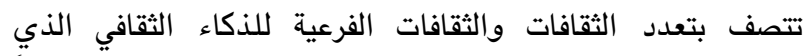

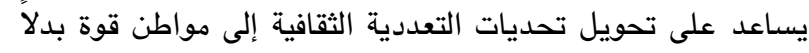

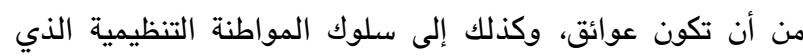

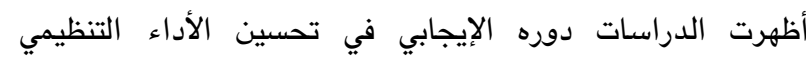

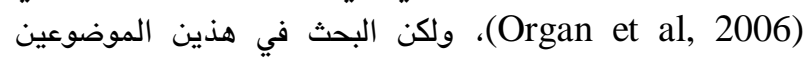

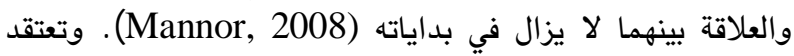

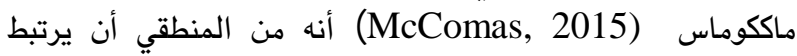

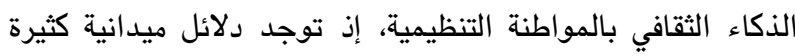

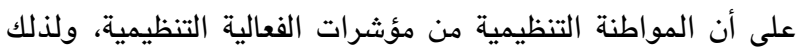
يجدر القيام ببحوث لتقصي هذه العلاقة. وقد قام كيونغ (Keung, 2011) بدراسة هدفت تقصي لئسي

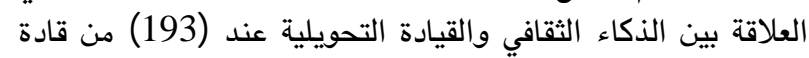

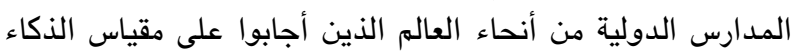

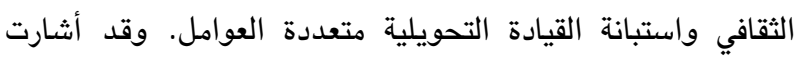

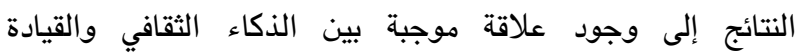

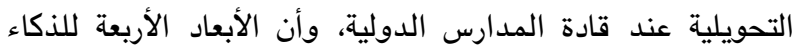
الثقافي تتنبأ بشكل كبير في العوامل الخمسة للقيادة التحويلية.
وقد حظي"الذكاء الثقافي"منذ مطلع القرن الحالي باهتمام

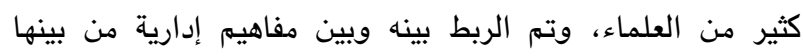
سلوك المواطنة التنظيمية ( Organizational Citizenship (Behavior

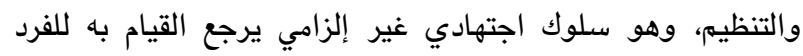

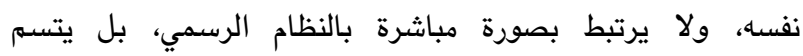

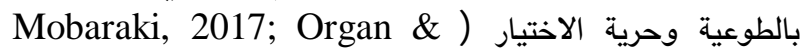
. (Lingl, 1994

ولهم يعد ينظر للذكاء من المنظور الضيق، عندما كان يقاس

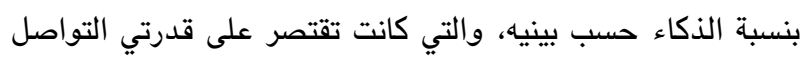

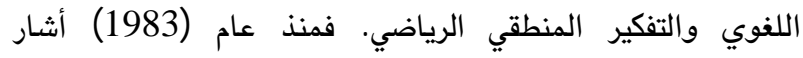
جاردنر إلى "الذكاءات المتعددة": الذكاء الذياء اللفوي والذكاء الذياء المنطقي

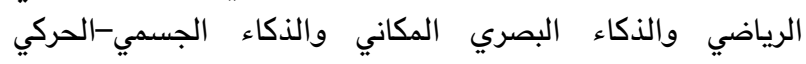

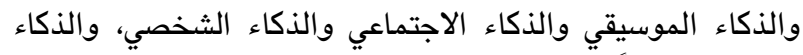

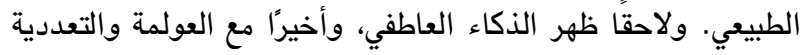

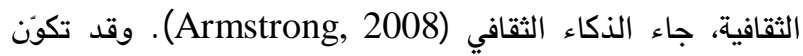

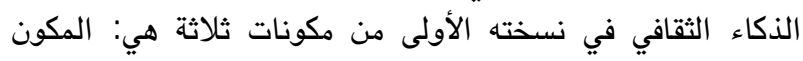

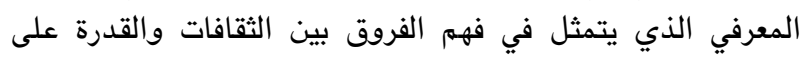

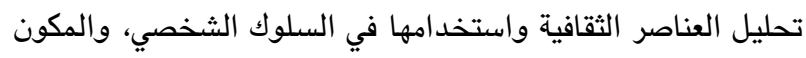

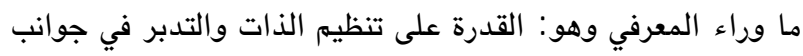

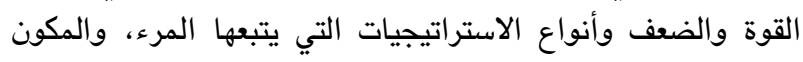

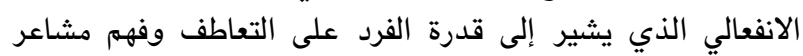
وأفكار الأفراد الذين ينتمون إلى ثقافات مختلفة ( Early \&

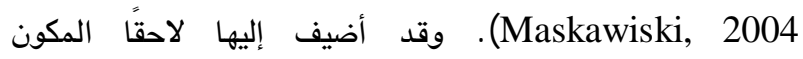

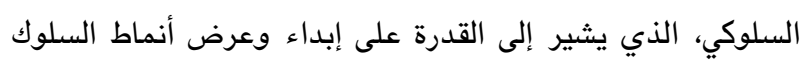

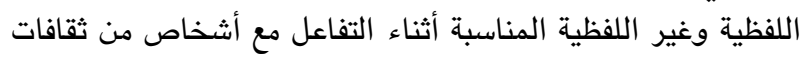

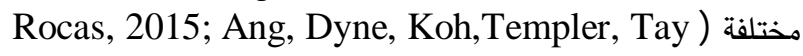

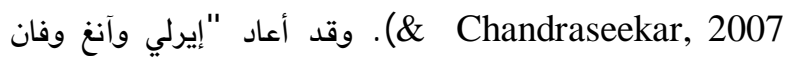

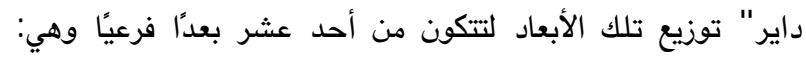

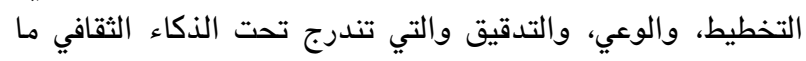

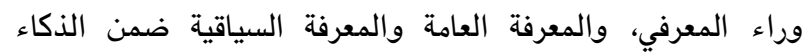

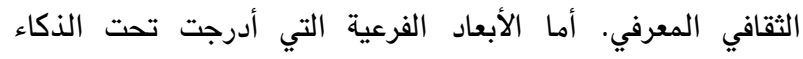

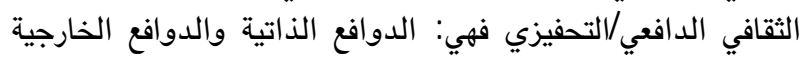

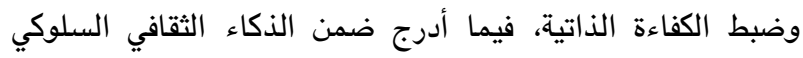

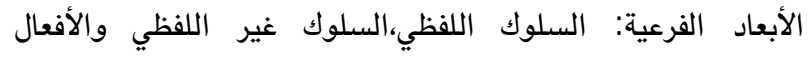

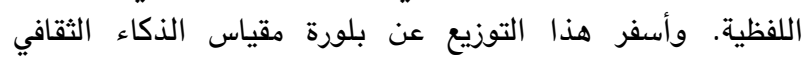

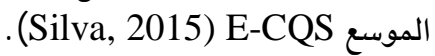

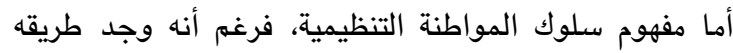

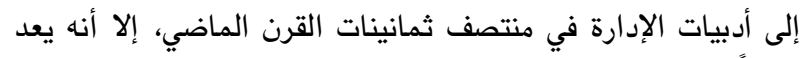

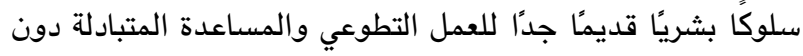

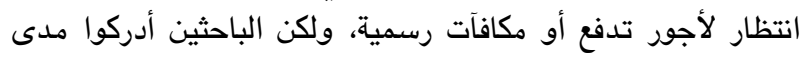

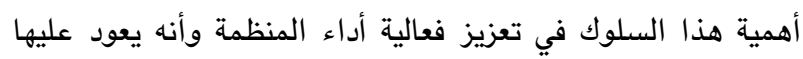

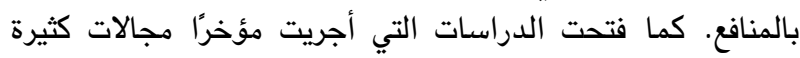


برامج أجنبية ودولية في محافظة عمّان وعلاقتها بدرجة ممارسة

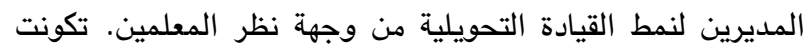

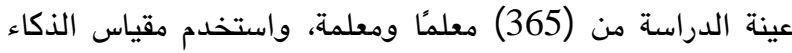
الثقافي للمديرين ومقياس لممارساتهم لنمط القيأ القيادة التحاء التحويلية.

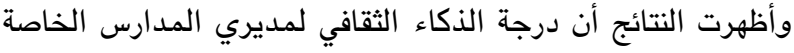

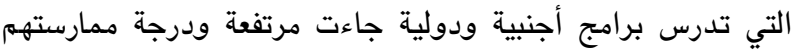

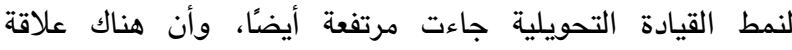
ارتباطية موجبة بين درجة الذكاء الثقافي ودرجة ممارستهم لنمط

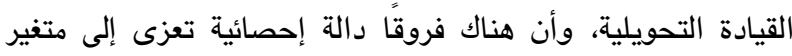

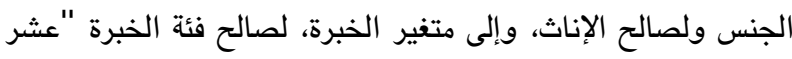

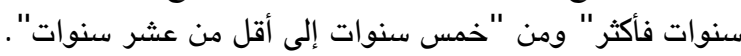

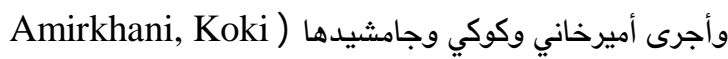

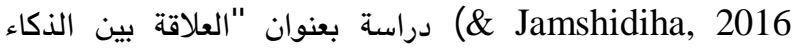

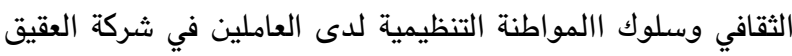

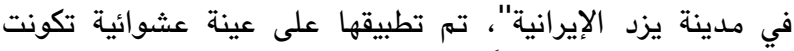

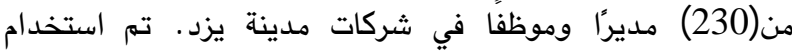

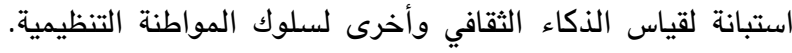

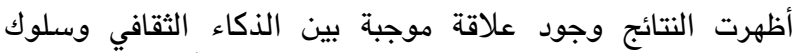

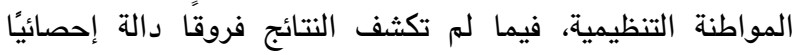

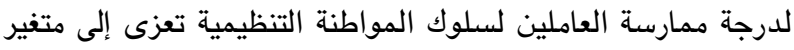

الجنس.

وقامت المظفر (Al-Mothafar, 2017) بدراسة هدفت إلى لى لئ

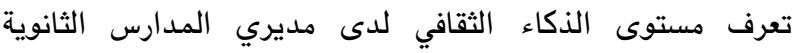

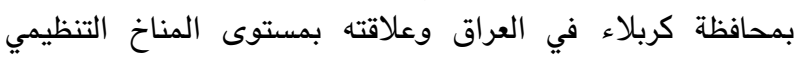
السائد في مدارسهـم. تكونت عينة الدراسة من الداء (364) معلمًا

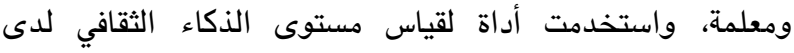

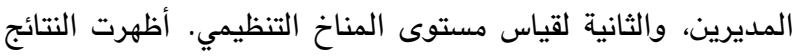

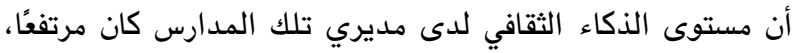

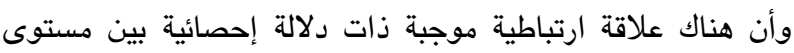

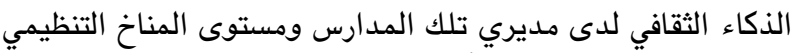

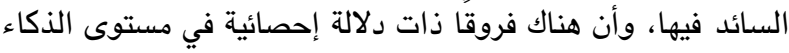

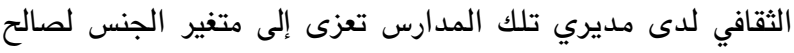

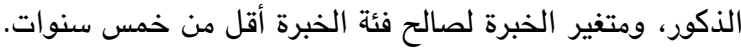
وفي دراسة الروسان (Al-Rousan, 2017) المعنونة بـ " لئية القيادة التحويلية والقيادة التبادلية لدى مديري الروسان المدارس الحكومية

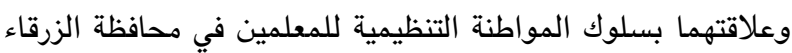

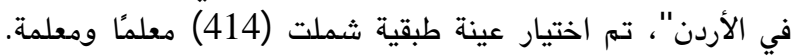

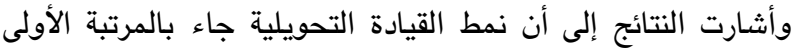

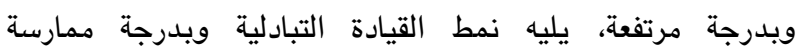
متوسطة، وأن درجة ممارسة سلوك المواطنة التنظيمية للمعلمين

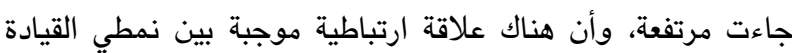
التحويلية والتبادلية وبين سلوك المواطنة التنظيمية.
Al-Harhsha \& Al- ) وأجرى الحراحشة والخريشا (Khuraisha, 2012 سلوك المواطنة التنظيمية وعلاقتها بالولاء التنظيمي لدى درى العاملين

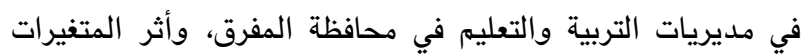

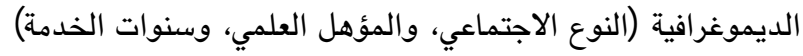

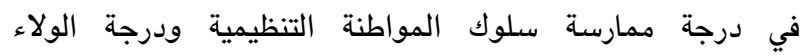
التنظيمي. تكونت عينة الدراسة من (206) من العاملين. أشارت

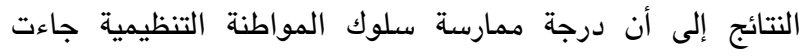

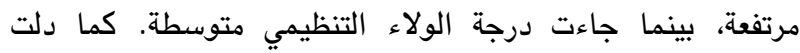

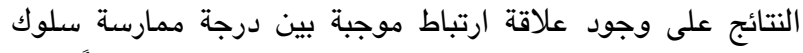

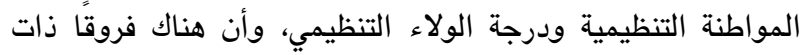

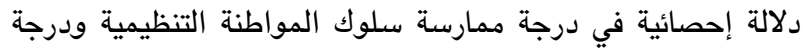

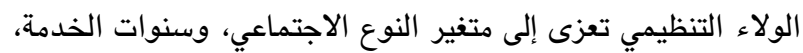

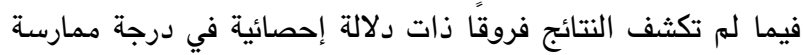
سلوك المواطنة التنظيمية يعزى إلى متغير المؤهل العلمي.

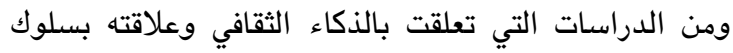

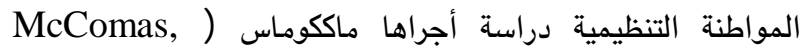

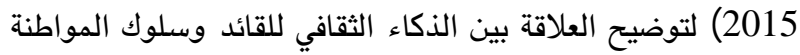

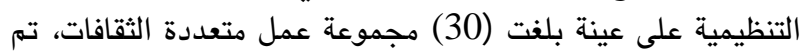

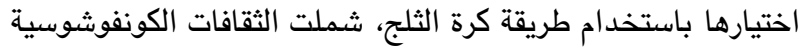

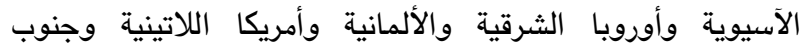

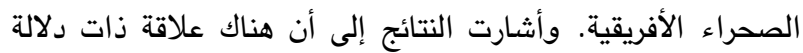

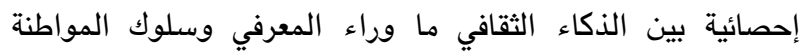

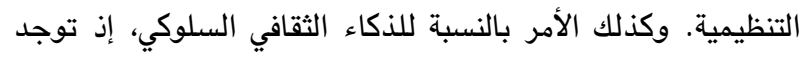

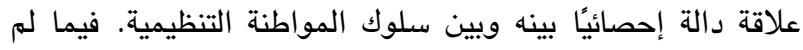

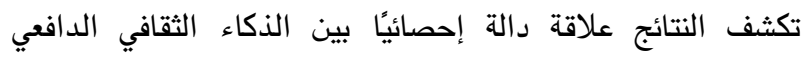
وسلوك المواطنة التنظيمية، كما لا توجد علاقة دالة إحصائيًا بين التين التياء الذكاء الثقافي المعرفي وبين سلوك المواطنة التنظيمية.

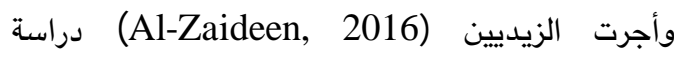

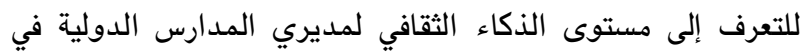

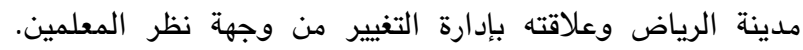

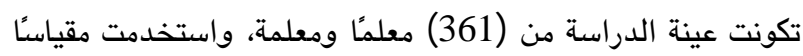

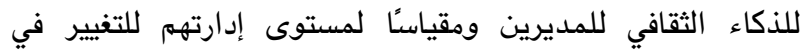

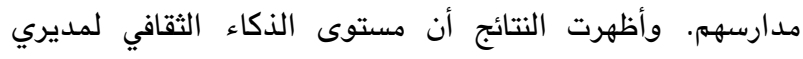
المدارس الدولية كان مرتفعًا، وأن مستوى إدارة التغيير لهؤلاء

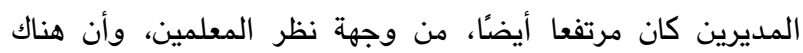

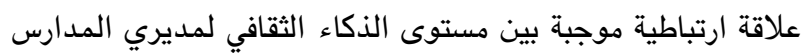

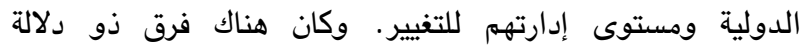

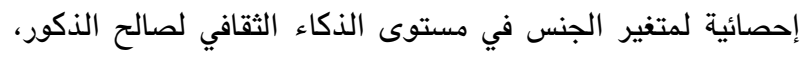

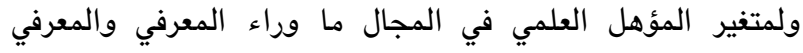
لصالح فئات الدراسات العليا.

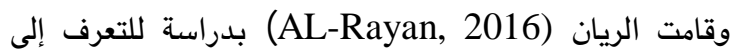
درجة الذكاء الثقافي لمديري المدارس الخاصة الأردنية التي تدرس 
التي ربطت بين المفهومين، غير أنها تتميز بأنها تطبق في المدارس الدولية التي تطبق مناهج أجنيية في الأردن.

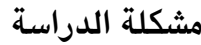

في ظل تنامي تعدد الثقافات الفرعية، خاصة في بعض البيئات ذات التعددية الديموغرافية، مثل المدارس الدولية التي تطبق برامج

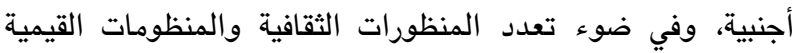
الناجمة عن الثورة الرقمية، تبرز أهمية الذكاء الثقافي لمديري

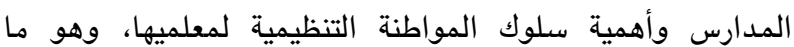

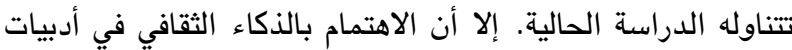

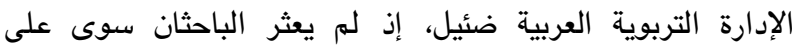

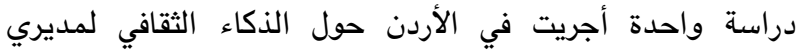

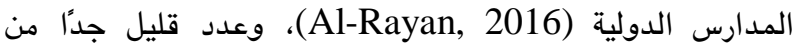

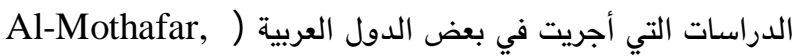

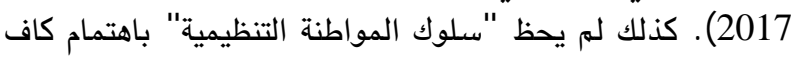

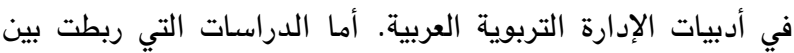

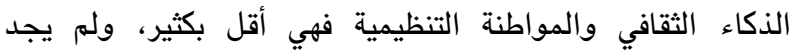

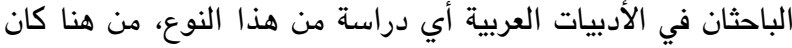

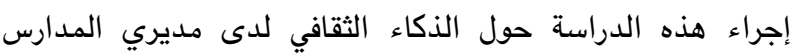

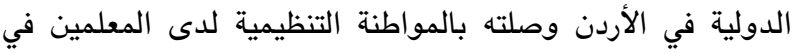
تلك المدارس من خلال محاولة الإجابة عن الأسئلة الآتية: 1- ما مستوى الذكاء الثقافي لدى مديري المدارس الدولية في محافظة عمّان من وجهة نظر المعلمين في تلك المدارس؟ 2- ما درجة ممارسة المعلمين لسلوك المواطنة التنظيمية في المدارس الدولية في محافظة عمّان من وجهة نظر المعلمين في تلك الك

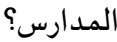
3- هل توجد علاقة ارتباطية دالة إحصائيًا (م=0.05 ) بين مستوى الذكاء الثقافي لدى مديري المدارس الدولية في محافظة

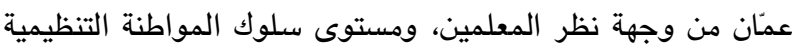

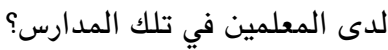
4-ما القدرة التتبؤية للذكاء الثقافي بسلوك المواطنة التنظيمية

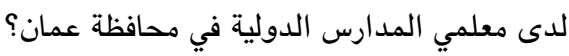

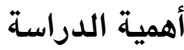

يأمل الباحثان على المستوى النظري، أن تسهم الدراسة

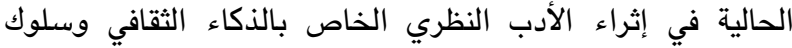
المواطنة التنظيمية والعلاقة بين المفهومين في المؤسسة التربوية التراية. وقد توفر الدراسة منطلقًا لدراسات يقوم بها باحثون آخرون. أما الأهمية العملية، فمن المؤمل أن تقدم الدراسة الحالية

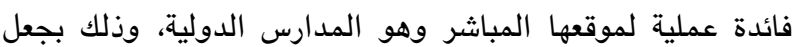

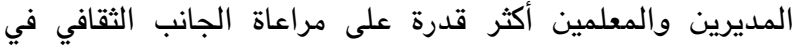
ممارساتهم وأكثر نجاحًا في البيئات المتعددة الثقافات. وقد تلفين الفيد
وأجرت الجعيثي (Al-Juaithi, 2017) دراسة هدفت التعرف

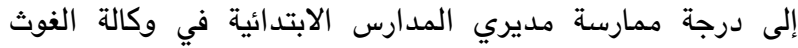

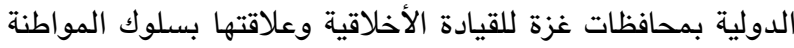
التنظيمية لدى معلميهم. بلغ عدد أفراد عينة الدراسة (450) معلمًا ومعلمة واستخدمت الباحثة استبانة القيادة الأخلاقية واستبانة سلوك المواطنة التنظيمية. وتوصلت إلى أن درجة ممارسة المديرين

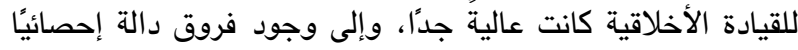

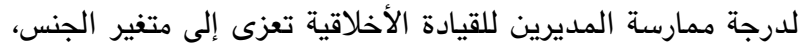

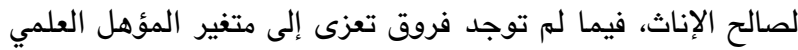
وسنوات الخبرة، وأن درجة ممارسة المعلمين لسلوك الماك المواطنة

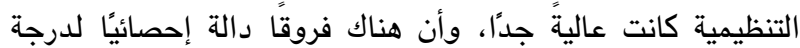

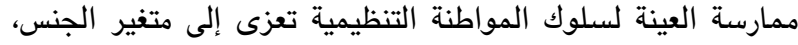

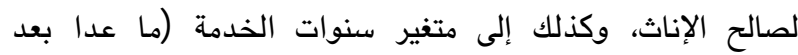

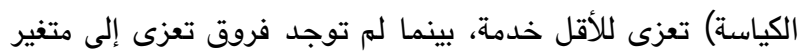

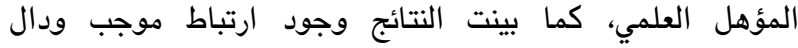
إحصائيًا بين درجة ممارسة المديرين للقيادة الأخلاقية ودرجة التهات ممارسة معلميهم سلوك المواطنة التنظيمية.

وهدفت دراسة أفيلا (Avila, 2018) للكثف عن دور

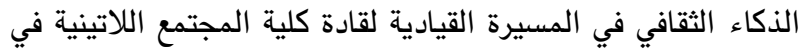

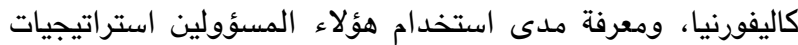

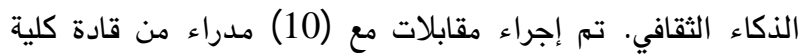
المجتمع اللاتينية في كاليفورنيا. وتوصلت النتائج إلى أن الذكاء

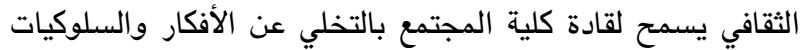

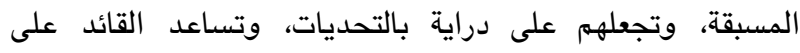
الوصول إلى أعلى إمكانياته، وأن التكيف مع التهاتيف الثقافة التنظيمية

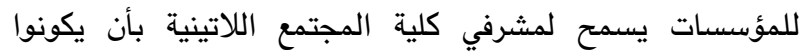
ناجحين، وأن التفاعل بين الجنس والهوية الثقافية يؤثر على كيفية

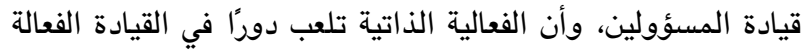
لمديري كلية المجتمع اللاتينية.

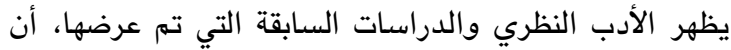

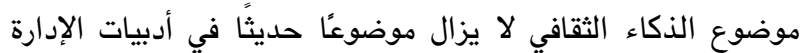

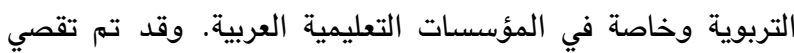
علاقة هذا المفهوم بمفاهيم أخرى كثيرة من بينها القيادة الأخلاقية

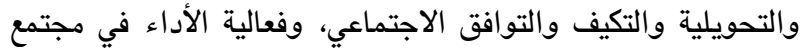
متعدد الثقافات. ومن بين المفاهيم التي ارتبط بها مفهوم "سلوك

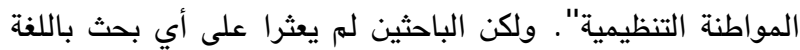

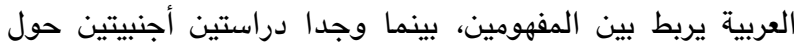

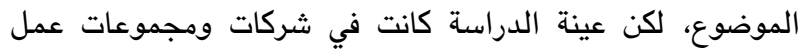

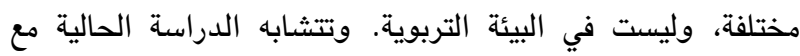

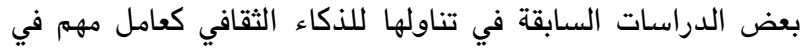

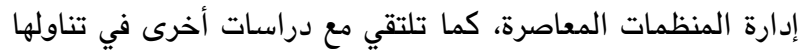
لموضوع سلوك المواطنة التنظيمية، وتلتقي مع الدراسات القليلة 
• سلوك المواطنة التنظيمية: فيتمثل في خمسة مجالات: الإيثار

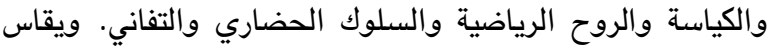

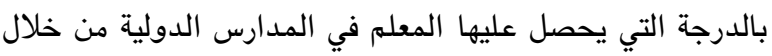

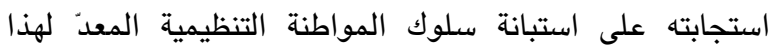

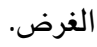
• المدارس الدولية في الأردن هي تلك المدارس التي حصلت على تولى موافقة بتطبيق برامج تعليمية أجنبية ودولية، والتي تقوم على الإنى الإني

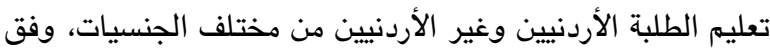

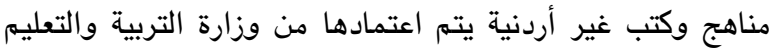
الأردنية (وزارة التربية والتعليه، إدارة التعليم الخاص) .

منهج الدراسة

استخدم الباحثان المنهج الوصفي الذي يقوم على دراسة

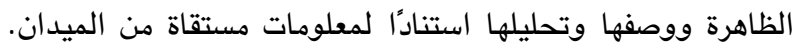
وهو أكثر المناهج البحثية استخدامًا وملاءمة لبحوث البقاد الإدارة

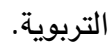

مجتمع الدراسة وعينتها

تكون مجتمع الدراسة من معلمي ومعلمات المدارس الدولية

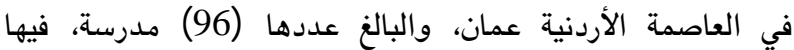

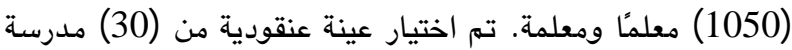

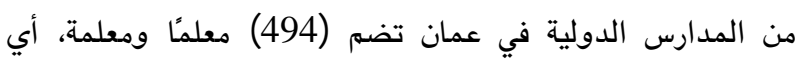
بنسبة (477\%) من مجتمع الدراسة، ويلغ عدد الاستبانات الصالحة للتحليل(473) استبانة.

أداتا الدراسة أولا: استبانة الذكاء الثقافي

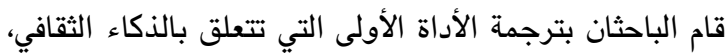

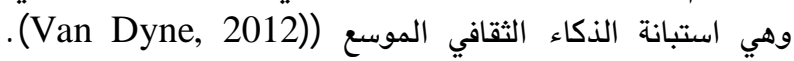

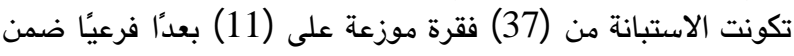

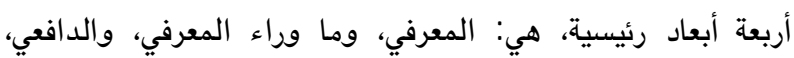

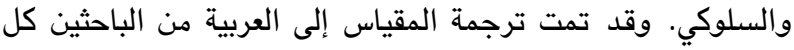

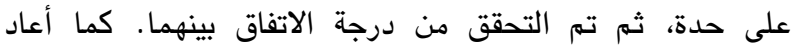

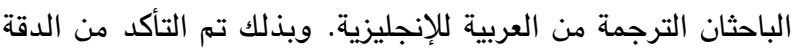

$$
\text { اللغوية للترجمة. }
$$

Ang, Van Dyne ( وقد أورد آنغ وفن داين وركوستوهل معاملات صدق بناء عالية للاستبانة (\& Rockstuhl, 2015

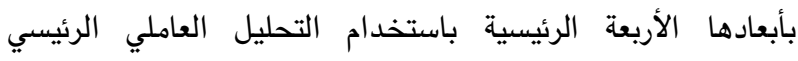

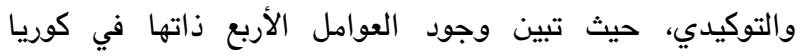

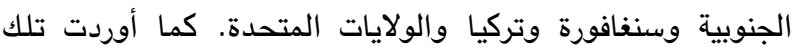

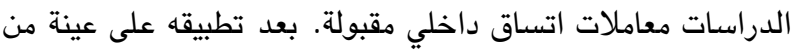
مكونة من (286) فردًا في (30) بلدًا.
في تصميم برامج تدريبية لزيادة الوعي الثقافي والحساسية الثقافية.

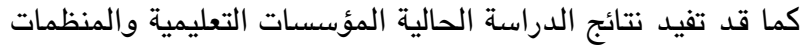

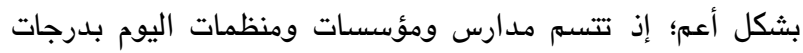

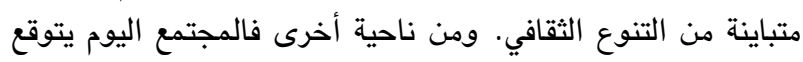

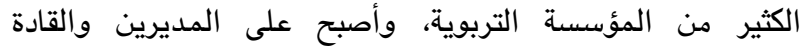

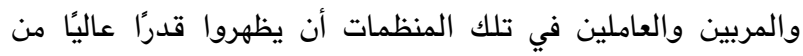

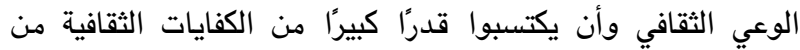
جهة، وأنماط سلوك المواطنة التظيمية من جهة أخرى.

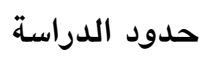

• طبقت الدراسة الحالية على عينة من معلمي المدارس الدولية التي

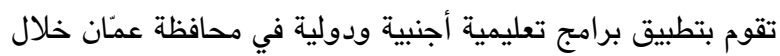
الفصل الدراسي الأول من العام الدراسي (2019/2018) .

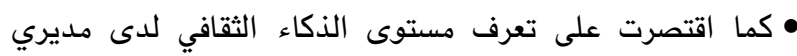

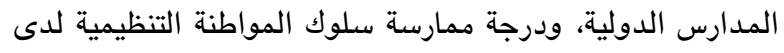
معلمي تلك المدارس والعلاقة بينهما . التعريفات الاجرائية • الذكاء الثقافي: هو قدرة المدير في المدرسة الدولية في الأردن

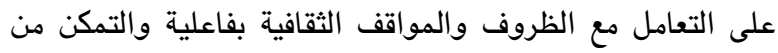

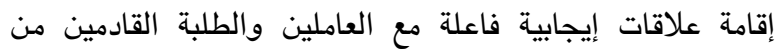
ثقافات وثقافات فرعية متباينة، ويقاس بالدرجة الكلية المتحققة

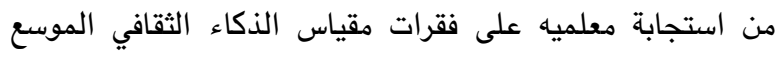
المستخدم في الدراسة الحالية. • الذكاء الثقافي المعرفي: هو الذيتئ الذراء المتعلق بمعتقدات وتقاليد

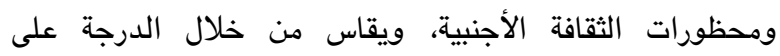
الفقرات الخاصة به في استبانة الذكاء الثقافي.

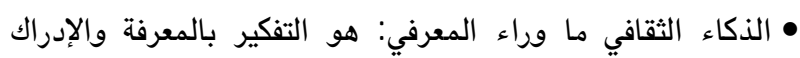

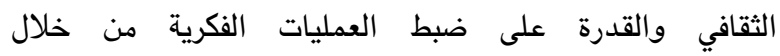

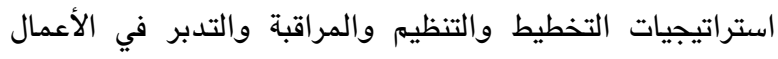

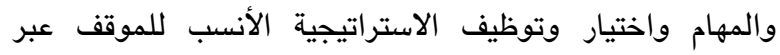

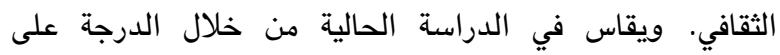
الذقرات الخاصة به في استبانة الذكاء الثقافي.

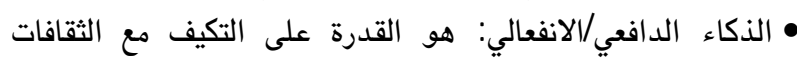

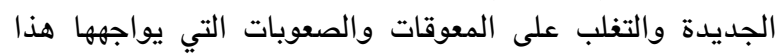

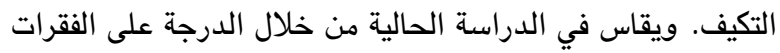
الخاصة به في استبانة الذكاء الثقافي.

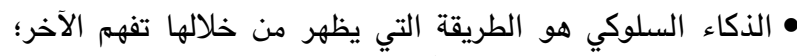

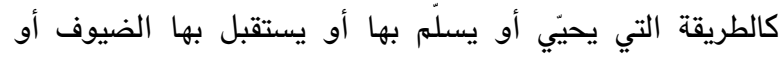

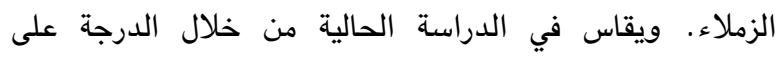
الفقرات الخاصة به في استبانة الذكاء الثقافي. 
وأية تعديلات يرونها مناسبة، وفي ضوء ملاحظات المحكمين تقرر

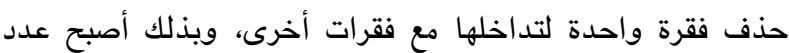
الفقرات (19) فقرة فئ واحدة

ثبات الاستبانة

تم التحقق من ثبات الاستبانة بطريقة الاختبار وإعادة الاختبار بتطبيق الاستبانة، وإعادة تطبيقها بعد أسبوعين (test-retest) على مجموعة من خارج عينة الدراسة مكوّنة من (50) معلمًا

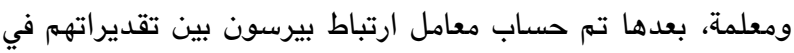
المرتين، كما تم حساب الاتساق الداخلي حسب معاب معادلة كرونباخ الداب ألفا، والجدول رقم (2) يبين معامل الاتساق الداخلي وثبات الإعادة

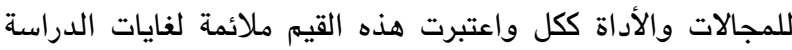

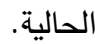

جدول (2): معامل الاتساق الداخلي كرونباخ ألفا وثبات الإعادة للمجالات والدرجة الكلية

سلوك المواطنة التنظيمية

\begin{tabular}{|c|c|c|}
\hline الداخلي & ثبات الإعادة & 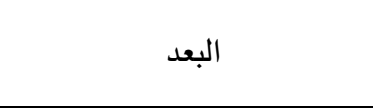 \\
\hline 0.74 & 0.86 & الإيثار \\
\hline 0.83 & 0.89 & الكياسة \\
\hline 0.78 & 0.88 & الروح الرياضية \\
\hline 0.82 & 0.86 & السلوك الحضاري \\
\hline 0.65 & 0.90 & 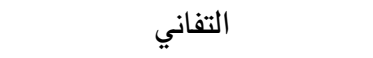 \\
\hline 0.92 & 0.91 & سلوك المواطنة التنظيمية ككل \\
\hline
\end{tabular}

التصحيح

تم استخدام تدريج ليكرت الخماسي لتصحيح أداتي الدراسة،

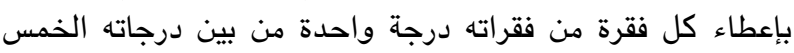

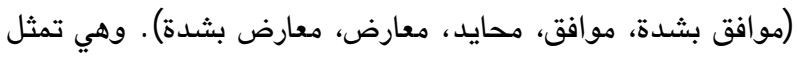

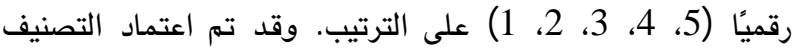

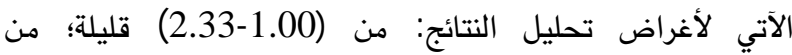
(3.67-2.34) متوسطة؛ ومن (5.00-3.68) كبيرة.

$$
\text { متفيرات الدراسة }
$$

اشتملت الدراسة على المتغيرات الآتية:

$$
\text { أولاً: المتغيرات الرئيسية }
$$

1- الذكاء الثقافي لدى مديري المدارس الدولية. 2- سلوك المواطنة التنظيمية لدى معلمي لمدارس الدولية.

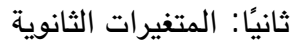
1. الجنس وله فيتّان: (ذكر، أنثى)
صدق الاستبانة

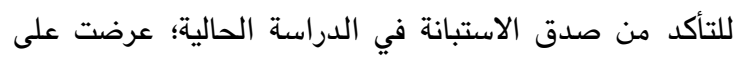

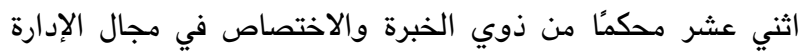

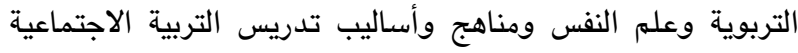

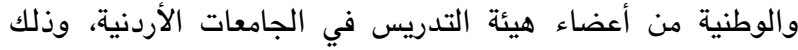

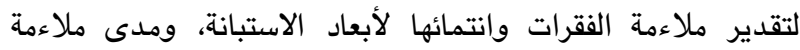

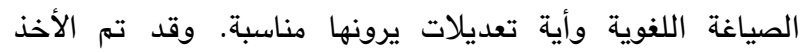

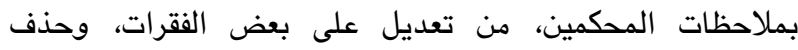
وإضافة بعض الفقرات، وتحديدًا، تم حذف ثلى ثلاث فقرات بناء على على ملاحظات معظم المحكمين.

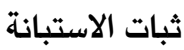

تم التحقق من ثبات الاستبانة في الدراسة الحالية بطريقة الاختبار وإعادة الاختبار (test-retest) بتطبيق الاستبانة وإعادة الادية

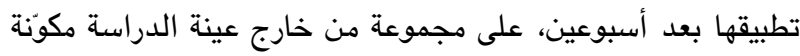

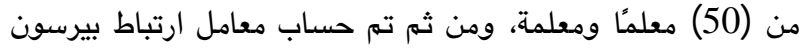

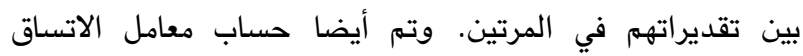

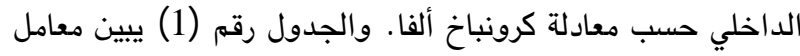

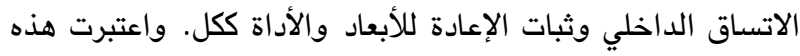
القيم ملائمة لغايات هذه الدراسة. جدول (1): معامل الاتساق الداخلي كرونباخ ألفا وثبات الإعادة

\begin{tabular}{|c|c|c|}
\hline \multicolumn{3}{|c|}{ الذكاء الثقافي } \\
\hline الداتساق & ثبات الإعادة & 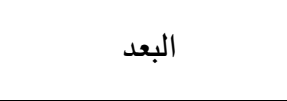 \\
\hline 0.94 & 0.93 & الذكاء ما وراء المعرفي \\
\hline 0.94 & 0.96 & ذكاء ثقافي معرفي \\
\hline 0.91 & 0.94 & السلوكي \\
\hline 0.95 & 0.95 & 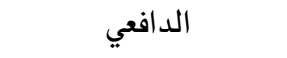 \\
\hline 0.97 & 0.96 & الذكاء الثقافي ككل \\
\hline
\end{tabular}
للمجالات والدرجة الكلية

ثانيًا: استبانة سلوك المواطنة التنظيمية

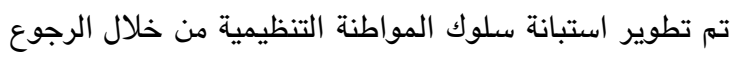
(Al-Amiri, إلى الأدب النظري والدراسات السابقة ذات العلاتئة 2003; Al-Maayat, 2005; Al-Rousan, 2017;

(Araydah, 2012

$$
\text { صدق الاستبانة }
$$

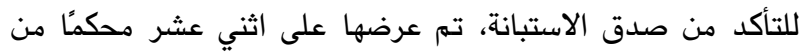

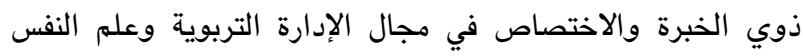

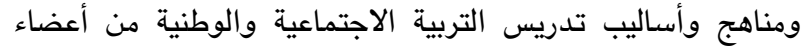

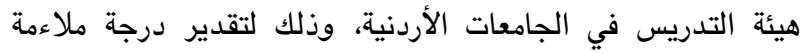

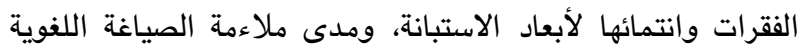


للإجابة عن هذا السؤال، حسبت المتوسطات الحسابية والانحرافات المعيارية لمستوى أبعاد الذكاء الثقافي لدى مدئ لديري

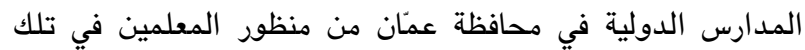
المدارس، والجدول (3) يوضح ذلك. محلكة
2. المؤهل العلمي: وله مستويان: (بكالوريوس، دراسات عليا) 3. سنوات الخبرة الوظيفية: وله مستويان: (أقل من 10 سنوات)،

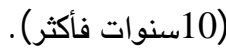

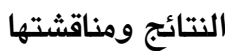
نتائج السؤال الاول: ما مستوى الذكاء الثقافي لدى مديري المدارس الدولية في محافظة عمان من منظور المعلمين في تلك الك الكي المدارس ومناقثتها؟

جدول (3) : المتوسطات الحسابية والانحرافات المعيارية لمستوى أبعاد الذكاء الثقافي لدى مديري المدارس الدولية في محافظة عمّان من منظور المعلمين في تلك المدارس مرتبة تنازليًا

\begin{tabular}{|c|c|c|c|}
\hline المستوى & الانحراف المعياري & المتوسط الحسابي & 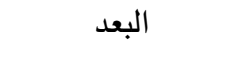 \\
\hline مرتفع & .813 & 3.98 & المعرفي \\
\hline مرتفع & .802 & 3.95 & ما وراء المعرفي \\
\hline مرتفع & .843 & 3.95 & السلوكي \\
\hline مرتفع & .793 & 3.95 & 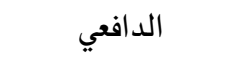 \\
\hline مرتفع & .757 & 3.96 & الذكاء الثقافي ككل \\
\hline
\end{tabular}

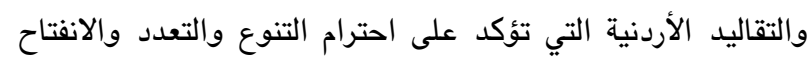

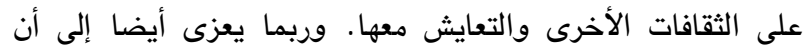

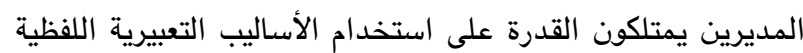

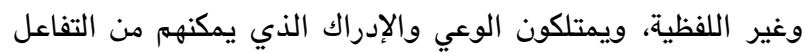

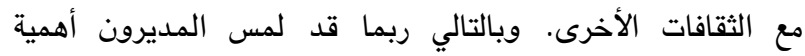
استخدام هذا النوع من الكفايات في تحقيق أهداف المؤسسات التي يعملون بها. واتفقت نتيجة الدراسة الحالية مع بعض مض نتائج الدراسات السابقة (

(Al-Mothafar,2017
يبين الجدول (3) أن المتوسطات الحسابية قد تراوحت مابين (3.95-3.98)، حيث جاء الذكاء المعرفي في المرتبة الأولى بأعلى ألى

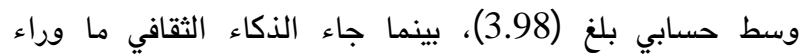

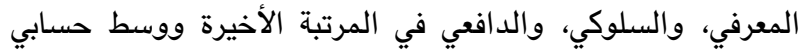

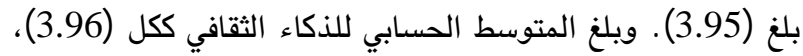

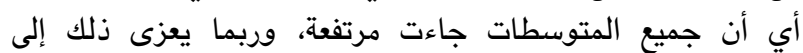
الخبرة التي يمتلكها مديرو المدارس الدولية لوجودهم في بيئة متنوعة ثقافيا؛ وممارستهم لمهارات الذكاء الثقافي بسبب التعامل

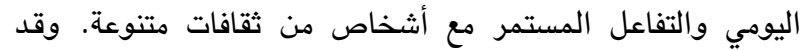
يعود ذلك إلى التنشئة الأسرية والاجتماعية والتمسك الفئ بالعادات

جدول (4): المتوسطات الحسابية والانحرافات المعيارية لاستجابة أفراد عينة الدراسة على فقرات الذكاء الثقافي مرتبة تنازليًا

\begin{tabular}{|c|c|c|c|}
\hline الانحراف المعياري & المتوسط الحسابي & 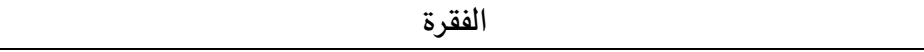 & رقم الفقرة \\
\hline .891 & 4.18 & يظهر مديري فهما للقيم الثقافية والسلوكيات المتباينة . & 1 \\
\hline .965 & 4.10 & يستخدم مدير مدرستي عبارات الترحيب والود التي تناسب السياق الثقافي. & 21 \\
\hline .952 & 4.05 & يظهر مديري فهما لشبكة العلاقات الاجتماعية وأدوار الجنسين. & 3 \\
\hline .912 & 4.05 & يركز مدير مدرستي على الانجاز عندما يتفاعل مع أشخاص من ثقافات مختلفة . & 12 \\
\hline .950 & 4.04 & يثق مدير مدرستي من أنه يستطيع أن يتفاعل مع أفراد من ثقافات أخرى. & 33 \\
\hline .931 & 4.04 & يمكن لمدير مدرستي تفهم وجهات النظر المتباينة ذات الصلة بالخلفيات & 4 \\
\hline .925 & 4.03 & ثقافات مدير مدرستي مِن استطاعته النجاح في التعامل مع الظروف المعيشية في & 31 \\
\hline .956 & 4.02 & ثقافات مأخرى مدرير مدرستي بالحركات الجسدية المناسبة عند التفاعل مع أشخاص من & 22 \\
\hline
\end{tabular}




\begin{tabular}{|c|c|c|c|}
\hline الانحراف المعياري & المتوسط الحسابي & 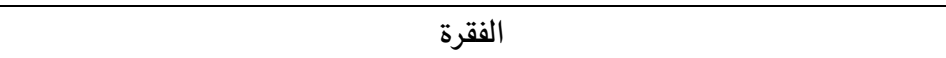 & 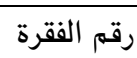 \\
\hline .915 & 4.02 & يظهر مدير مدرستي فهما لأوجه التشابه والاختلاف بين الأنظمة القانونية & 2 \\
\hline .941 & 3.99 & 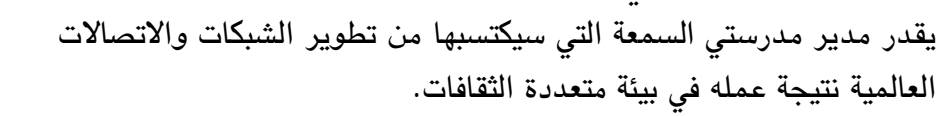 & 30 \\
\hline .960 & 3.98 & يمتلك مدير مدرستي المقدرة على التعامل مع الضفوط الناجمة عن التعامل مع & 32 \\
\hline .993 & 3.98 & يتبع مدير مدرستي خطط عمل قبل التفاعل مع الناس من ثقافة مختلفة . & 11 \\
\hline .930 & 3.98 & يمكن لمدير مدرستي فهم أساليب القيادة عبر الأوضاع الثقافية المتباينة. & 6 \\
\hline 1.016 & 3.97 & مع السياقات الثقافية المحددة. فيري اللفظية (اللكنة ونغمة الصوت، ومعدل الكلام) لتتناسب & 20 \\
\hline .978 & 3.97 & أخرى. محرص مدير مدرستي على إثراء ثقافته عبر تفاعله مع أشخاص من ثقافات & 16 \\
\hline .928 & 3.95 & يتحقق مدير مدرستي من دقة معرفته الثقافية خلال التفاعلات بين الثقافات. & 17 \\
\hline .924 & 3.95 & يفيد مدير مدرستي من التعامل مع الثقافات الجديدة. & 27 \\
\hline .982 & 3.94 & وأفي مدير مدرستي بكيفية تأثير ثقافة الآخرين على أفكارهم ومشاعرهم & 15 \\
\hline .966 & 3.94 & يراعي مديري الخلفيات الثقافية عندما يطلب منهم شيئا. & 25 \\
\hline .952 & 3.94 & الثحَدَّثُ مدير مدرستي معرفته الثقافية للإفادة من ذلك في الحد من سوء فهم & 18 \\
\hline .948 & 3.94 & يشعر المتعاملون مع مدير مدرستي من أبناء الثقافات المتباينة بالارتياح. & 7 \\
\hline 1.013 & 3.93 & يستخدم مدير مدرستي استراتيجيات التفاوض الفعالة عبر الثقافات المتباينة. & 8 \\
\hline .921 & 3.92 & يعتقد مدير مدرستي أنه يستفيد كثيرا من العيش أو العمل في ثقافة مختلفة. & 29 \\
\hline .902 & 3.92 & مختلفة، مدير مدرستي أن ثقافته تؤثرعلى تفاعلاته مع أشخاص من ثقافات & 13 \\
\hline 1.045 & 3.91 & يغيرمدير مدرستي طريقته في التوقف عن الحديث أوالسكوت بما يلائم المواقف & 19 \\
\hline .997 & 3.91 & يتصرف مدير مدرستي بطريقة تراعي الثقافات الأخرى عند اختلاف وجهات & 24 \\
\hline .970 & 3.90 & يستطيع مديري التعامل بفاعلية مع الصراع في الثقافات المتباينة. & 10 \\
\hline 1.046 & 3.89 & يستخدم مدير مدرستي أساليب مختلفة لتحفيز الناس عبر الثقافات المتباينة. & 9 \\
\hline .953 & 3.89 & يدرك مديري كيفية تأثر وضع ما بأبعاد ثقافية محددة. & 14 \\
\hline .938 & 3.89 & يستمتع مديري بالتفاعل مع أشخاص من ثقافات مختلفة & 26 \\
\hline 1.035 & 3.86 & باستطاعة مديري التحدث وفهم العديد من اللفات. & 5 \\
\hline .961 & 3.84 & (وليست مماثلة لثقافته ) . مجمي مجوعات من أشخاص لديهم خلفية ثقافية مختلفة & 28 \\
\hline 1.087 & 3.81 & الاجلال مديري الطريقة التي يحيي بها الآخرين (المصافحة، الانحناء، طريقة & 23 \\
\hline
\end{tabular}

والعشرين" يغير مدير مدرستي الطريقة التي يحيي بها الآخرين

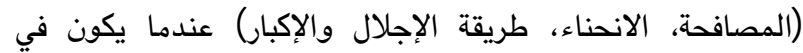

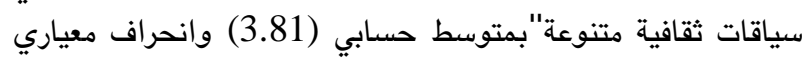

أظهرت النتائج في جدول (4) أن المتوسطات الحسابية

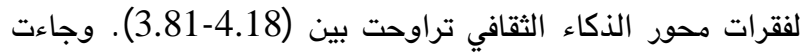
الفقرة الأولى "يظهر مدير مدرستي فهما للقيم الثقافية والسلوكيات الفيات

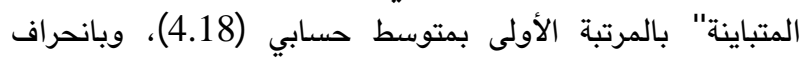
معياري (891.)، وجاءت في المرتبة الأخيرة الفقرة الثالثة 
يوضح جدول (5) المتوسطات الحسابية والانحرافات المعيارية لدرجة ممارسة المعلمين لسلوك المواطنة التنظيمية في

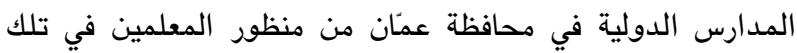

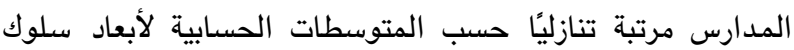

نتائج السؤال الثاني: ما درجة ممارسة المعلمين لسلوك المواطنة التنظيمية في المدارس الدولية في محافظة عمان من منظور المعلمين في تلك المدارس ومناقشتها؟ المواطنة التنظيمية.

جدول (5): المتوسطات الحسابية والانحرافات المعيارية لاستجابة أفراد عينة الدراسة على ابعاد سلوك المواطنة التنظيمية مرتبة تنازليًا

\begin{tabular}{|c|c|c|c|}
\hline المستوى & الانحراف المعياري & المتوسط الحسابي & 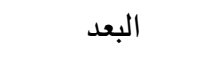 \\
\hline مرتفع & .612 & 4.52 & التفاني \\
\hline مرتفع & .677 & 4.42 & الكياسة \\
\hline مرتفع & .686 & 4.39 & السلوك الحضاري \\
\hline مرتفع & .728 & 4.22 & الروح الرياضية \\
\hline مرتفع & .791 & 4.05 & ال الإيثار \\
\hline مرتفع & .596 & 4.31 & المواطنة ككل \\
\hline
\end{tabular}

المعلمين يدركون بشكل كاف أهمية الاستجابة لتوجهات المديرين

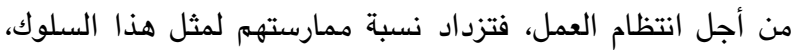

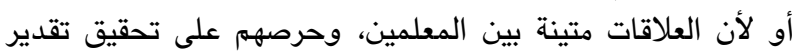

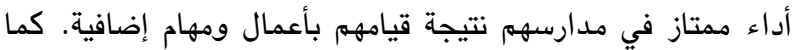

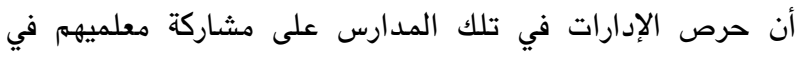

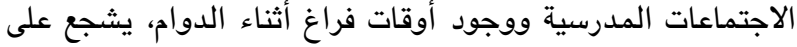

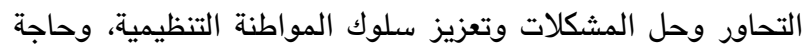

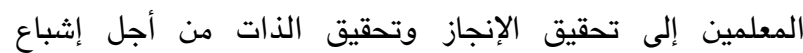
حاجاتهم، مما يجعلهم على قدر من الإحساس بالمسؤولية تجاه

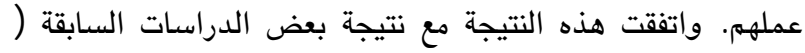
Al-Harahsha \& Al-Juaithi, 2017; Al-Rousan 2017;

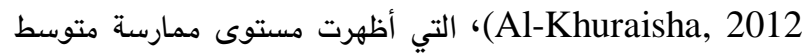
لسلوك المواطنة التنظيمية لدى المعلمين. ويبين الجدول (6) أوساط فقرات استبانة سلوك المواطنة التنظيمية مرتبة تنازليًا :
يبين الجدول (5) أن المتوسطات الحسابية قد تراوحت ما بين (4.05-4.52)، حيث جاء بعد التفاني في المرتبة الأولى بأعلى تراتى وسط حسابي بلغ (4.52)، بينما جاء الإيثار في المرتبة الأخيرة وبمتوسط حسابي بلغ (4.05)، وبلغ المتوسط الحسابي لسلوك

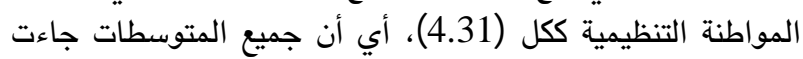
مرتفعة؛ وقد يعزى ذلك إلى القيم والأعراف المنبثقة عن الثقافة الثة

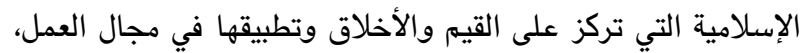
والأجواء السائدة في العمل التي تعزز ولاء التئ المعلمين لمدارسهم

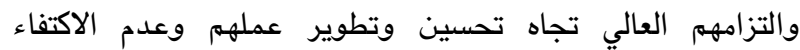

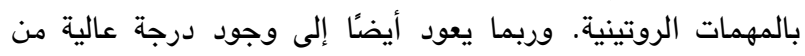

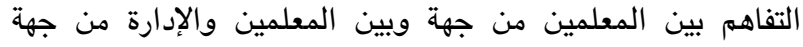
أخرى، ومراعاة المديرين لظروف المعلمين، والثقة المتبادلة بينهم. وقد يعود إلى الظروف المادية التي يمتاز بها معلمو المدارس المديرين الدولية التي قد تجعل المعلم يتحمل أعباء العمل وممارسة

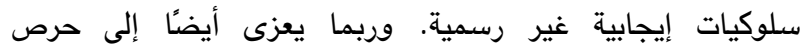

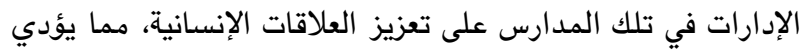

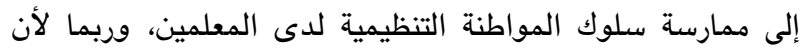

جدول(6): المتوسطات الحسابية والانحرافات المعيارية لاستجابة أفراد عينة الدراسة على فقرات بعد سلوك المواطنة التنظيمية مرتبة تنازليًا

\begin{tabular}{|c|c|c|c|}
\hline الانحراف المعياري & المتوسط الحسابي & 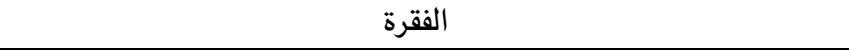 & 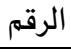 \\
\hline .682 & 4.62 & ألتزم بتعليمات المدرسة وأنظمتها حتى في حال عدم تواجد الرقابة & 52 \\
\hline .765 & 4.52 & أحترم خصوصية زملائي · & 39 \\
\hline .768 & 4.49 & أدافع عن سمعة مدرستي عندما ينتقدها الآخرون. & 49 \\
\hline .742 & 4.49 & أهتم بتوجهات رؤسائي في العمل . & 51 \\
\hline .775 & 4.46 & ألىاظب على قضاء معظم ساعات العمل في أداء واجبات العمل الموكولة & 50 \\
\hline .807 & 4.45 & أهتم بحقوق زملائي الوظيفية . & 40 \\
\hline .901 & 4.36 & أتجنب تصيد أخطاء العاملين في المدرسة . & 43 \\
\hline
\end{tabular}




\begin{tabular}{|c|c|c|c|}
\hline الانحراف المعياري & المتوسط الحسابي & 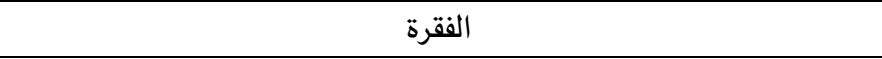 & 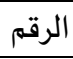 \\
\hline .826 & 4.36 & أتشاور مع الزملاء عند اتخاذي أي قرار قد يؤثر عليهم أو يهمهم. & 41 \\
\hline .822 & 4.38 & 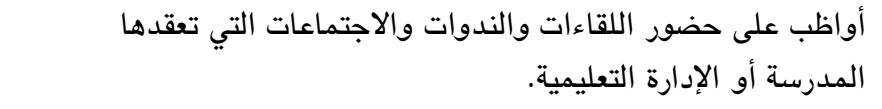 & 47 \\
\hline .821 & 4.34 & أزود زملائي بما لدي من معارف ومهارات تساعدهم على أداء عملهم. & 38 \\
\hline .808 & 4.33 & أعمل على تسهيل مهمة زملائي الجدد حتى وإن له يطلب مني ذلك. & 35 \\
\hline .850 & 4.31 & أقوم بأداء عمل زملائي في حال تغيههم. & 34 \\
\hline .807 & 4.42 & أبذل قصارى جهدي لتعليم نفسي وتحسين مهاراتي، حتى لو على نفقتي & 48 \\
\hline .922 & 4.27 & أحرص على متابعة جميع أنثطة المدرسة متابعا باهتمام كل ما يصدر & 46 \\
\hline .929 & 4.23 & أبتعد عن أسلوب الشكوى في التعامل مع مشكلات العمل. & 42 \\
\hline .927 & 4.17 & أتسامح عن أي إساءة شخصية ، وأتجنب لوم الآخرين. & 44 \\
\hline .947 & 4.12 & أظهر المجاملة لزملائي حتى في أوقات التوتر الشخصي أو المهني. & 45 \\
\hline 1.062 & 3.89 & مشكلات متعلقة بالعمل. أستافيا خارج الوقت الرسمي لمساعدة الآخرين الذين لديهم & 36 \\
\hline 1.225 & 3.68 & أتطوع لتقديم نشاطات إضافية للتلاميذ خارج أوقات العمل الرسمي. & 37 \\
\hline
\end{tabular}

نتائج السؤال الثالث: هل توجد علاقة ارتباطية دالة إحصائيا

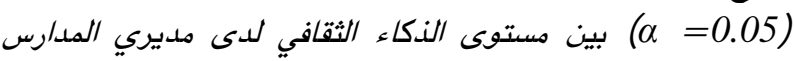

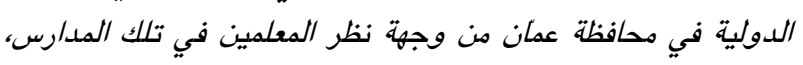

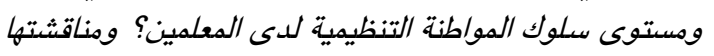

للإجابة عن هذا السؤال، تم حساب معامل ارتباط بيرسون

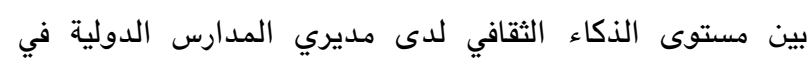

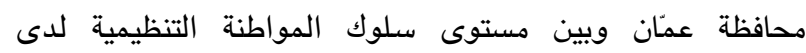
المعلمين في تلك المدارس، والجدول (7) يوضح ذلك.
يظهر الجدول (62-68) أن المتوسطات الحسابية تراوحت بين المداء

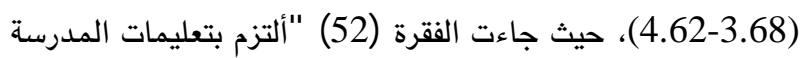

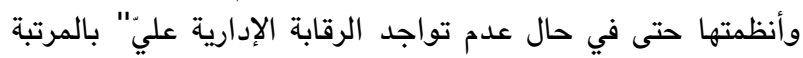

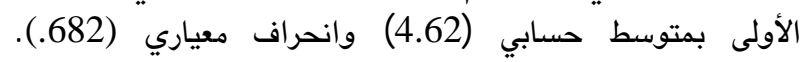

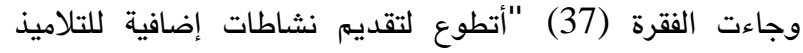

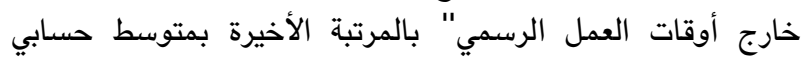
(3.68) وانحراف معياري (1.225).

جدول(7) : معامل ارتباط بيرسون للعلاقة بين مستوى الذكاء الثقافي لدى مديري المدارس الدولية في محافظة عمّان وبين مستوى سلوك

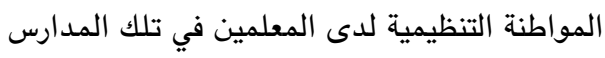

\begin{tabular}{|c|c|c|c|c|c|c|}
\hline الذكاء الثقافي ككل & الدافعي & السلوكي & المعرفي & ما وراء المعرفي & & \\
\hline$* * .456$ & $* * .445$ & $* * .447$ & $* * .442$ & $* * .381$ & معامل الارتباط & الإيثار \\
\hline **.404 & $* * .413$ & $* * .390$ & $* * .397$ & $* * .323$ & معامل الارتباط & الكياسة \\
\hline$* * .435$ & $* * .433$ & $* * .430$ & $* * .413$ & $* * .361$ & معامل الارتباط & الروح الرياضية \\
\hline$* * .430$ & $* * .423$ & **.389 & $* * .415$ & $* * .381$ & معامل الارتباط & السلوك الحضاري \\
\hline$* * .415$ & $* * .438$ & $* * .378$ & $* * .406$ & $* * .339$ & معامل الارتباط & التفاني " \\
\hline$* * .508$ & $* * .508$ & $* * .484$ & $* * .491$ & $* * .424$ & معامل الارتباط & سلتوك المواطنة \\
\hline
\end{tabular}

ممارسة سلوكيات طوعية. كما أن المدير الذي يتسم بالذكاء

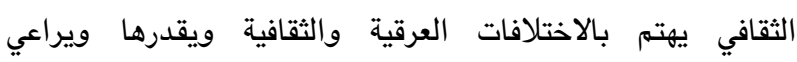

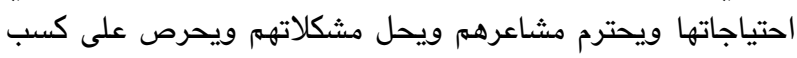

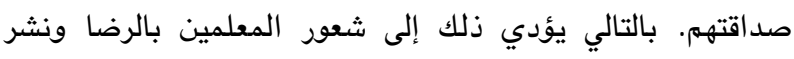

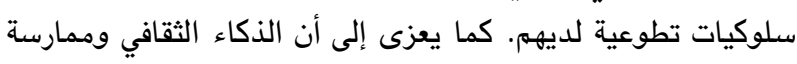

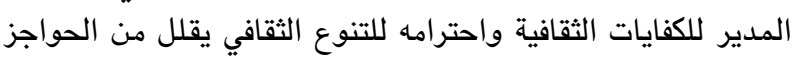

يتبين من الجدول (7) وجود علاقة موجبة دالة إحصائيا بين

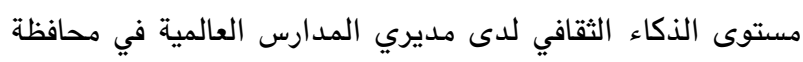

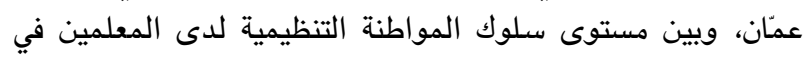

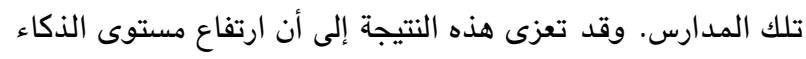
الثقافي لدى المديرين يؤهلهم إلى التفاعل الإيجابي مع المعاع المعلمين،

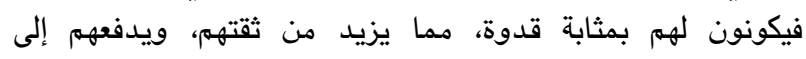


ممارسة الكفايات الثقافية المنبثقة من الذكاء الثقافي ينتقل بالضرورة

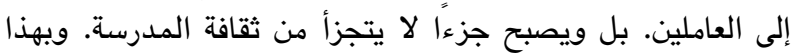
يرتقي سلوك المواطنة التنظيمية لديهمه. لإنجأ

نتائج السؤال الرابع: ما القدرة التنبؤية للذكاء الثقافي بسلوك

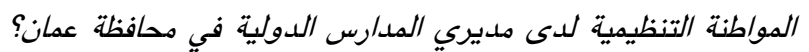
ومناقثتها

للإجابة عن هذا السؤال، تم استخدام تحليل الانحدار

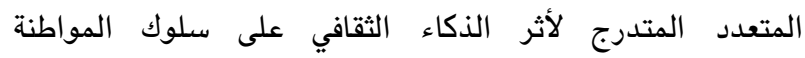

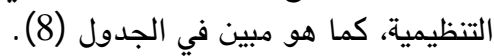

بينه وبين المعلمين والعاملين عمومًا، ويحسن من جودة الخدمات

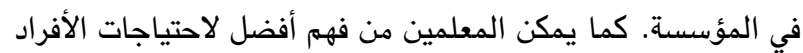
المختلفين ثقافيًا عنهم.

واتفقت هذه النتيجة مع نتائج بعض الدراسات السابقة

Amirkhani, Koki \& Jamshidiha, 2016;) McComas,2015). كما تجد هذه النتيجة تأييدًا لها في أدبيات الذكاء الثقافي والكفايات الثقافية بشكل عام في معظم المجالات الخدمية ( Egan \& Hansuvadha \& Slater, 2012; حيث أشارت تلك الدراسات أيضًا إلى أن \&endick, 2008

جدول (8) : تحليل الانحدار المتعدد المتدرج لأثر الذكاء الثقافي على سلوك المواطنة التنظيمية

\begin{tabular}{|c|c|c|c|c|c|c|c|}
\hline لالإلة فئية & قيمة ف & $\mathrm{R}^{2}$ & $\begin{array}{c}\text { التباين المفسر }{ }^{2} \\
\text { R }\end{array}$ & الارتباط & $\begin{array}{c}\text { المعامل } \\
\text { B }\end{array}$ & المتنبئات & المتغير التابع \\
\hline .000 & 163.655 & .258 & .258 & .508 & .241 & الذكاء الدافعي & \multirow{2}{*}{ سلوك المواطنة } \\
\hline .000 & 89.221 & .017 & .275 & .525 & .170 & الذكاء المعرفي & \\
\hline
\end{tabular}

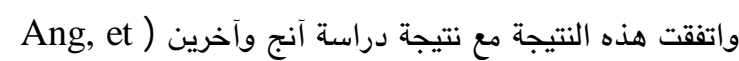

(al, 2007 ودراسة كيونغ (Keung, 2011).

التوصيات

في ضوء النتائج التي توصلت إليها الدراسة، يمكن اقتراح

التوصيات الآتية: - n

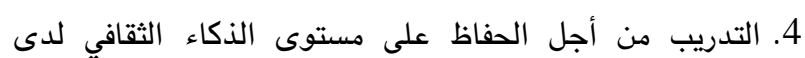

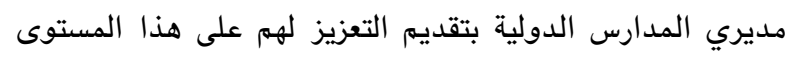

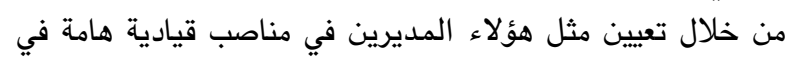

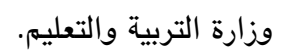

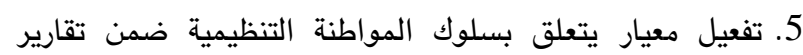

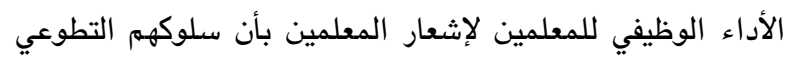

$$
\text { موضع اهتمام وتقدير. }
$$

6. اشتراط التميز في الذكاء الثقافي للمتقدمين إلى وظيفة مدير

للمدارس.
يتبين من الجدول (8) أن الذكاء الثقافي الدافعي والذكاء

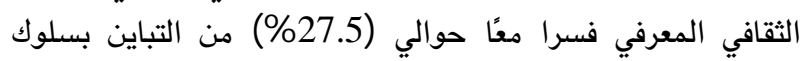

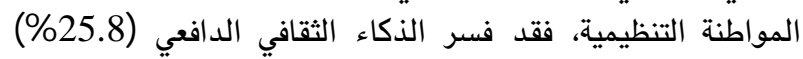

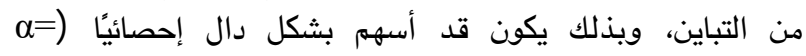

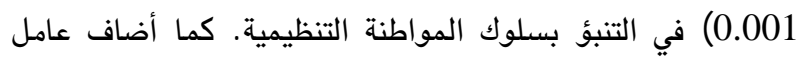

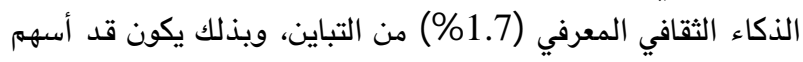

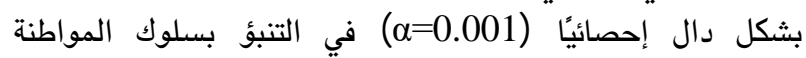

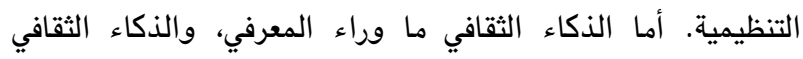

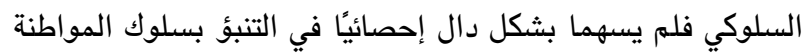

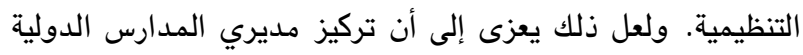

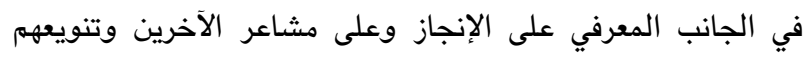

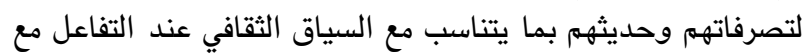

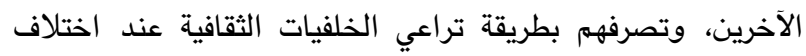
وجهات النظر، يسهم بشكل أو بآخر ويؤثر بسلوكيات المواطنة

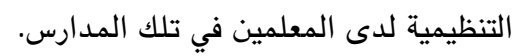

كما أن اكتساب مديري المدارس الدولية لمهارات الذكاء

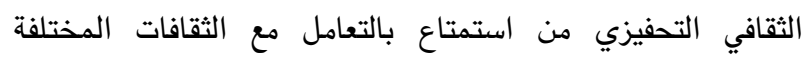

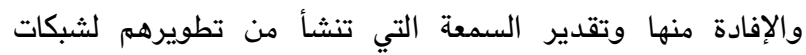

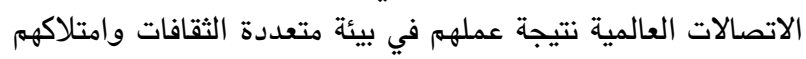

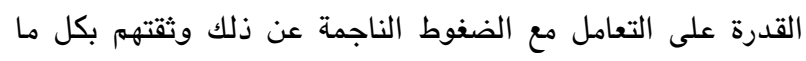

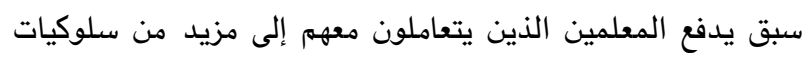

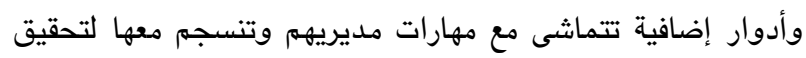
الفاعلية والارتقاء بالمنظمة التي يعملون بها هات مدارئ 


\section{References}

Ang, S. , Dyne, L., Koh, C., Ng, K., Templer, K., Tay, C., \& Chandraseekar, N. (2007). Cultural intelligence: Its measurement and effect on cultural judgment and task performance. Management and Organization Review, 3(3), 335-371.

Ang, S., Dyne, L., \& Rockstuhl, I. (2015). Cultural intelligence, In: Michele J. Gelfand, ChiyueChiu, \& Ying-yiHong (Eds.). Handbook of advances in culture and psychology, Oxford: Oxford University Press.

Amirkhan, A., Koki, M., \& Jamshidiha, M. (2016). The relationship between cultural intelligence and organizational citizenship behavior in Aqiq Tile Employees in Yazd. Journal of Accounting, Financial and Economic Sciences, 2(1), 10-17.

Al-Amiri, A. (2003). Determinants and effects of the behavior of organizational citizenship in organizations, Journal of King Abdul Aziz University, 17(2), 67-83.

Al-Araydah, R. (2012). Ethical leadership level for directors of government high schools in Amman and its relationship to the level of practice of organizational citizenship from the teachers' perspectivem, Master Thesis, Middle East University, Jordan.

Al-Harashsha, M \& Al-Khuraisha, M. (2012). Degree of practice of organizational citizenship behavior and its relationship to organizational loyalty among workers in the directorates of education in Mafraq Governorate, Mu'tah Research and Studies, 27(2), 5778.

Al-Juaithi, Kh. (2017). The degree of principals' practice of ethical leadership and their relation to the behavior of organizational citizenship among their teachers, Master Thesis, Islamic University, Gaza.

Al-Maayta,A.(2005). The degree of the practice of Jordanian secondary school principals in organizational justice and its relation to the behavior of the organizational citizenship of their teachers, Ph.D. Dissertation, Amman Arab University,Jordan.
Al-Mothafar, M. (2017). Cultural intelligence among high school principals in Karbala Governorate in Iraq and its relation to the prevailing organizational climate in their schools from the point of view of teachers, MA Thesis, Middle East University, Jordan.

Al-Rayan, N. (2016). The degree of cultural intelligence of Jordanian private school principals studying foreign and international programs in Amman Governorate and their relationship to the degree of managers' practice of transformational leadership styles from the point of view of teachers, MA Thesis, Middle East University, Jordan.

Al-Rousan, E. (2017). Transformational leadership and reciprocal leadership among public school principals and their relation to the behavior of organizational citizenship of teachers, International Specialized Educational Journal, 6(12), 166-181.

Al-Sheemat, Kh. (2007). Organizational citizenship behavior among high school teachers in Jordan and their relation to their functional performance, Ph.D. Dissertation, Amman Arab University, Jordan.

Al-Zahrani, M. (2007). Organizational citizenship behavior among teachers of general government schools for boys in Jeddah from the point of view of the principals and teachers of these schools, Master Thesis, Umm Al Qura University, Saudi Arabia.

Armstrong, Th. (2008). Multiple intelligence in the classroom. 3rd ed., ASCD, Alexandria: Virginia, USA.

Avila, P., (2018). Latina community college leaders and the role cultural intelligence plays in their leadership, PhD. Dissertation, Brandman University.

Early, P., \& Mosakowski, E. (2004). Cultural intelligence. Harvard Business Review, 83(2), 139-146

Egan, M, \& Bendick, M. (2008). Combining multicultural management and diversity into one course on cultural competence, Academy of Management Learning and Education, 7(3), 387-393. 
Hansuvadha, N., \& Slater, C. (2012). Culturally competent school leaders: The individual and the system, The Educational Forum, 76(2), 174-189.

Keung, E. (2011). What factors of cultural intelligence predict transformational leadership: A study of international school leaders. Ph.D. Dissertation, Liberty University, Lynchburg: VA.

Khan, S., \& Rashid, M. (2015). The mediating effect of organization commitment in the organization culture, leadership and organization justice relationship with organizational citizenship behavior: A study of academics in private higher learning institutions in Malaysia. International Journal of Recent Advances in Organizational Behavior and Decision Sciences, 1(2), 334-352.

Maamary, H. \& Mansour, Z. (2014). Organizational citizenship behavior as a tool for organizational effectiveness in modern organizations, Journal of Human and Social Sciences, 14. 43-54.

Mannor, M. (2008). Top executives and global leadership. In: Ang, S. \& VanDyne. L (Eds), Handbook of cultural intelligence: Theory, measurement, and applications . Armonk, NY: M.E.Sharp.

McComas, A. (2015). The relationship of a leaders cultural intelligence to organizational citizenship behaviors in a multiculturealwork group, Ph.D. Dissertation, Indiana Wesleyan University.
Mobaraki, N. (2017). Organizational citizenship approach for teachers of intermediate education: An empirical study of the mediators of boushkroun municipality, Master Thesis, University of Mohamed Khader, Algeria.

Organ, D., \& Lingle, A. (1995). Personality, satisfaction and organizational citizenship behavior. The Journal of Social Psychology. 135(3), 339-350.

Organ, D., Podsakoff, M., \& Mackenzie, S. (2006). Organizational citizenship behavior:Its nature, antecdents, and consequences. Personnel Psychology, 59(2), 484-487.

Silva, F. (2015). Psychometric properties of the expanded cultural intelligence scale in South African context, Master Thesis, University of Pretoria.

Soria, K., \& Troisi, J. (2014) Internationalization at home alternatives to study abroad: Implications for students' development of global, international, and intercultural competencies, Journal of Studies in International Education, 18(3), 261-280.

Tabatabei, N. Takapoo, F., \& Leilaeyoun, A. (2015). The effects of job satisfaction on organizational citizenship behavior, International Journal of Academic Research in Business and Social Sciences, 5(1), 155-165.

Taha, M. (2006). Human intelligence: Contemporary trends and monetary issues, Kuwait: National Council for Culture, Arts and Letters. 